\title{
"Pseudo-dermal sinus tract or spinal dermal sinus-like stalk?" Reply to Drs. Cornips, Weber, Vles, and Van Aalst's Letter to the Editor
}

\author{
Juan F. Martínez-Lage
}

Received: 18 May 2011 /Accepted: 31 May 2011 / Published online: 10 June 2011

(C) Springer-Verlag 2011

\section{Dear Editor,}

I would like to thank Dr. Cornips et al. [1] for their kind letter and valuable comments that provide an excellent summary of the findings of our work published in Child's Nervous System on the differentiation of spinal dermal-sinus tracts and a lesion that we designated as "pseudo-dermal sinus tract" [2]. We feel very much honored for their sympathetic and thoughtful comments and believe Dr. Cornips et al. completely agree with the opinions and hypotheses put forward in our paper. In our article, we amply recognized the important research on the subject made by Dr. Van Aalst and coworkers that came to our attention during the preparation of our abovementioned paper and that we enjoyed very much reading [3]. We also appreciate the beautiful and illustrative clinical and surgical photographs that Dr. Cornips et al. include in their Letter to the Editor regarding our article in Child's Nervous System [1].

In addition, after the online publication of our work, we were aware of a brilliant and exhaustive work by Dr. D. Pang and coworkers that appeared almost simultaneously with our publication [4]. I personally wrote a letter to Dr. Pang to congratulate him and his team for their thorough research that I would also like to recommend reading to the journal's readers interested on this subject. In this work, the authors describe an entity they have designated as limited dorsal myeloschisis (LDM). Dr. Pang et al. report 51 instances of LDM and describe the cutaneous and intraspinal findings of this entity [4]. We think that many cases included in Dr. Pang et al.'s work closely resemble the tracts reported by Van Aalst and coworkers and those of our paper

\section{J. F. Martínez-Lage $(\bowtie)$}

Regional Service of Neurosurgery,

Virgen de la Arrixaca University Hospital, 30120 Murcia, Spain

e-mail: juanf.martinezlage@cablemurcia.com
$[2,3]$. However, we would like to emphasize that we intentionally excluded from our survey saccular and lipomatous cutaneous lesions as, in our opinion, they do not correspond with the tracts we reported and do not produce much confusion at the time of differential diagnosis [2].

Dr. Cornips et al. raise the crucial question of the nomenclature utilized to refer to these solid tracts and prefer using the term dermal sinus-like stalk while we chose to name these lesions as pseudo-dermal sinus tracts. These investigators manifest their concerns about the confusion that might originate among clinicians (pediatricians, neuroradiologists) involved in the diagnosis and management of these tracts. In our literature review, we found several terms to refer to these lesions as meningocele manqué, rudimentary meningocele, hamartomatous stalk, and meningothelial tract. The advantage of using the denomination of "pseudo-dermal sinus tract" rests on the belief that articles referring to these lesions would be probably searched for in electronic databases under the heading "spinal dermal-sinus." However, we think that it is not the name that matters most but the concepts on the true clinical significance of these lesions.

\section{References}

1. Cornips EMJ, Weber JW, Vles JSH, van Aalst J (2011) Pseudo-dermal sinus tract or spinal dermal sinus-like stalk. Child's Nerv Syst (in press)

2. Martínez-Lage JF, Almagro MJ, Ferri-Ñiguez B, Izura Azanza V, Serrano C, Domenech E (2011) Spinal dermal sinus and pseudo-dermal sinus tracts: two different entities. Childs Nerv Syst 27:609-616

3. van Aalst J, Beuls EAM, Cornips EMJ, van Straaten HWM, Boselie AFM, Rijkers K, Weber JW, Vles JSH (2009) The spinal dermal-sinus-like stalk. Childs Nerv Syst 25:191-197

4. Pang D, Zovickian J, Oviedo A, Moes GD (2010) Limited dorsal myeloschisis: a distinctive pathological entity. Neurosurgery 67:1555-1580 